\title{
IMPROVEMENT OF NATIONAL STRATEGIC FRAMEWORK IN ORGANIC PRODUCTION AND MANAGEMENT IN THE REPUBLIC OF BULGARIA
}

\author{
Venelin Terziev $^{1 *}$, Ekaterina Arabska ${ }^{2}$ \\ ${ }^{1}$ Professor, Ph.D., D.Sc. (National Security), D.Sc. (Ec.), University of Rousse, Rousse, Bulgaria, \\ National Military University, Veliko Tarnovo, Bulgaria, terziev@skmat.com \\ ${ }^{2}$ Associate Professor, Ph.D., University of Agribusiness and Rural Development, Plovdiv, Bulgaria, \\ katya.arabska@gmail.com \\ ${ }^{*}$ Corresponding author
}

\begin{abstract}
The study examines organic sector development in the Republic of Bulgaria, as a sector showing significant growth in last ten years, in the context of its potential and contribution for sustainable rural development. Identification and analyses of the main factors in organic farming development reveal its positive characteristics but also underline the main problems in its development in the country as: lack of information, communication and coordination between stakeholders in the country; spontaneous and unsubstantiated management decisions in organic holdings; lack of strategic planning on all the levels (national, local and organizational). Lead by the implication that sector development should be first encouraged and shaped by appropriate state policies and strategies, the paper makes proposals for new instruments and approaches in the strategic planning on the national level accenting business environment, institutional support and administrative activities, production peculiarities, marketing realities, knowledge and advisory services' needs, information provision and motivation.
\end{abstract}

Keywords: Sustainable development, rural regions, strategic planning.

\section{INTRODUCTION}

The processes of globalization in modern world put many problems and questions before states and international community. Sustainable development is a fundamental goal interrelating economic and ecological effectiveness for wise use of natural resources and keeping ecological balance. The objective of reaching high values of food safety is closely related to sustainable agricultural development and organic production in particular as a sector in permanent growth in the last years possessing high potential and bearing in mind the close relation to other sectors (Arabska, 2013b).

The agricultural sector is essential for the management of the EU, the development of the rural economy and the provision of food, public goods and services and the increasing the efficiency and competitiveness of the agricultural sector are determined as key objectives (Kuzmanova, 2012). In its policy the EU has put many 
times an emphasis on organic production as one of the methods for achieving sustainable development. In general, the main goal in agriculture's development in the EU is the achievement of high levels of food safety, economic, ecological and social sustainability. The Common Agricultural Policy (CAP) also appeals for promoting quality instead of quantity. Furthermore, the choice of consumers in the EU is directed towards healthier and tastier food with high nutritional values produced by environmentally friendly methods- organic farming in particular (Arabska, 2014b). The leading principle in this development is the quality. Consumers now search not only for the 'rude' quality first- easily determined facts in relation to safety and hygiene but for the 'soft' one too where traditions, heritage and sustainable production give added value to the products. A market-oriented farmer/producer should respond to consumers' demands in order to sell the produce, especially in respect to quality and safety.

From its advent as a way of thinking and agricultural practice at the beginning of $\mathrm{XX}$ century organic farming has been expanding and embracing more and more countries and areas. Last years' sector growth is assessed as permanent and stable. Organic agriculture follows world-wide accepted principles which are transformed according to local economic, climatic and cultural characteristics. Application of specific standards, control and labelling scheme are characteristic for organic agriculture and processing. Many countries have official policies for organic sector development. The questions what is the real development in each one country and how to monitor trends are still open (Arabska, 2014b). Studies on organic sector development are provoked by the progressive development of the sector worldwide and increasing demand of organic products on one hand, and on the other- by the favourable prerequisites which exist in the country, as well as of the opportunities that this sector provides to small and medium business, rising its competitiveness and fostering rural development. Organic production is economically effective, ecologically compatible and socially responsible and it occurs to be 'an innovative solution for creating entrepreneurial initiatives in rural regions (Nikolova, 2012) aiming at increase in competitiveness by applying an ecological technology using a new approach- planning, management and control over the production and management processes. The objectives of all institutions involved in organic production, should be pointed towards greater possibilities for organic farming. Stimulating organic production by payments and subsidies can be considered as unquestionable (Kayryakov, 2010).

The development of the Bulgarian agriculture is suffering from the same negative tendencies that are similar in most industrial countries. Policies for rural development in the country contribute to sustainable development as a priority, in full satisfaction of the increasing demands on safety and food quality, product differentiation, animal welfare, environmental quality and protection of the natural and rural environment. Bulgaria is one of the richest European countries regarding biological and landscape diversity. In combination with soil and water pureness, this is a prerequisite for successful development of organic production. Unfortunately, negative trends in last few decades led to changes in land function and its big fragmentation, as well as to abandonment of small villages. Now, when ways are actively sought for effective use of the country's potentials in agriculture, the methods of organic farming as a multifunctional system which integrates economic and social issues with those of environmental protection, turn to be a proper alternative for producers, processors and traders to find the best solution for organization, management and development of their farms, production or trade enterprises and to find markets for their products.

Current study considers organic sector development from the point of view of the following characteristics of organic production: sustainable management of natural resources, high standards for food quality and safety; human attitude towards animals, economic effectiveness, employment opportunities and rural development. It provides some important implications about the need of new approaches and instruments for strategic organic management on the national level aiming at long-term actions addressing the serious gaps in the management of the overall production process, as is the essence of that production method, because of the focus on the technological aspects and neglect of the management and permanent control of all the processes in organizations.

\section{STATE-OF-ART OF ORGANIC PRODUCTION SECTOR IN THE REPUBLIC OF BULGARIA}

Development of agricultural and food sector in the country is closely connected to rural regions development suffering a number of problems concerning depopulation and abandonment in last few decades but still staying of the greatest significance for economic development of the country. The increased growth in organic production is provoked by the market expansion in European and world scope. The main motif for development of activities in organic sector is the expectation for a good profit, followed by profitable direction of agribusiness, family and community benefits and healthy food (Nikolova, 2012).

The positive trends in the growth of organic production are noticed in Bulgaria too as it is shown in the information provided by the Ministry of agriculture and food for the development of the organic agriculture in 
Bulgaria. In recent years in Bulgaria organic agriculture is one of the sectors developing fast in conditions of crisis and permanently increasing the areas and number of operators in the organic control system. Although the revealed positive data, the availability of the corresponding legislation and the institutional support, the question of the marketing of organic produce stays as one of the most topical: the trends that more than $90 \%$ of certified organic produce in the country to be exported presented in a national marketing research available on the site of the Ministry of agriculture and food stay the same for several years (Goranova et al., 2012), and mostly those of raw materials (primary, non-processed produce) export are kept and to Bulgarian consumer final import products are offered which (along with the low level of information, the lack of clear identification of organic products and easy confusion with so-called ecological products) inevitably leads to unaffordable prices and low market shares of organic produce as a whole.

The organic agricultural activities in the country are mostly implemented by small and medium enterprises and farmers. That way they could not reach the levels needed for gaining market advantages. The market opportunities are big but the risks are even bigger. The profit in agricultural sector is low as a principle and this impedes the production increase. It is necessary an agricultural system to be established which to support the close connections to producers and to improve the innovation activities. Now, when we are on the way to the new program period and when data were already collected and analyzed in order to make the new strategic and program documents, the question if these data and analyses were objective or enough is very important (Arabska, 2013b).

An investigation of behaviour, wish and opportunities of operators and consumers for organic production development in the country in connection to the strategic goals of sustainable development show that the lack of information about essence, principles and advantages of organic production is very prominent (Arabska, 2013a). The low level of information, difficulties in identification and consumers' trust, limited choice and low incomes are pointed as the limiting problems for sector development. Lack of information, weak social attention, undeveloped trade with local organic products in local markets and the predominance of foreign trade marks certified organic products are among the negative factors for organic sector development (Arabska, 2013a). That investigation shows a big gap between the groups of operators, and organic operators in particular, and the group of the consumers. Consumers prefer shopping in big trade chains while a very little part of examined operators sell their produce to them. One of the problems is the requirements of big chains for having fresh produce all over the year and providing variety of products in order to satisfy consumers' needs. This is a problem for both organic and conventional producers in the country. Orientation of the consumers' choice to big chains, because of a number of reasons (advertising, campaigns, comfort, trademarks, quality, etc.), leads to the lack of market not only for local organic products but for local agricultural produce as a principle. Thus, the question of providing demanded quality is not only the case for organic producers. But the problem of reaching high enough prices in order to cover production expenses and make a profit, as well as the certainty in produce sales, orientate the organic producers to markets abroad. The problem here is in providing enough quantity in order transport expenses to have sense.

The approach to rely on the increasing demand of healthy food of high quality is wrong for organic sector development. The above underlined lack of information in some general directions shows that this way any substantial changes in the near future could not be expected. Furthermore, one of the most important challenges which organic producers will continue to face in the future is the negative impact of the imported produce. The low purchasing power in the country is a basic factor too. The export orientation of organic production in the county (especially of raw materials) leads to import of processed products from the raw materials but the prices are higher. These processed products however are searched for by the customers because of the understanding that they are of 'higher quality'. The wrong approach to export raw materials which at first sight makes a profit in fact turns to be disastrous for economic development of the country as a whole and hence for the quality of life, as well as for the employment.

Financial obstacles that are usually stated as the basic ones for organic sector development in fact require a completely different approach. Reaching financial independence is a slow process and this is a problem not only for organic sector development. Unfortunately, the common wish falls in the two extremes: making great profit in a very short term and avoiding investments in business or living on credits, „draining” European money and some other things like these. Life quality is dependent on society in which people live, not of that they are striving after or of the money they have. The above described situation shows that it is not enough only to set the global goals in terms of strategies, plans and laws, but to point the concrete actions for their implementation which could be executed only if they have a broad public support.

A study underlines the main problem to be the approach in the provided financial support from the European and national programs and the lack of a real marketing planning and strategy making (Arabska, 2014a). The need of providing knowledge and information in organic production (customer value of organic products) and 
farm management, expenditures control, price-making, risk management, add value initiatives, sales, distribution and promotion is obvious.

Bearing in mind that the legislative frame is available as well as the necessary soil, climatic, natural and other resources, the crucial role for organic sector development will have the increase in the level of information and motivation amongst business sector, non-profit sector and consumers about the potential of organic production for achieving sustainable growth, entrepreneurship encouragement and cooperation in storage, processing, marketing and sales. The need of development a brand new strategy and a plan for organic sector development based on the integrated approach and including clear, real and effectively controlled objectives and actions is more prominent than ever.

\section{ORGANIC PRODUCTION IN STATE AND LOCAL STRATEGIES OF THE REPUBLIC OF BULGARIA}

Challenges before humanity in XXI century connected to climatic changes, insufficiency of resources, pollution of environment, dynamics in international business and uncertainty in economic and political sphere lead to a number of questions regarding sustainable development not only in the sense of „protecting nature for future generations" but also of development of steady in economic, ecological and social relation productions and first of all in internationally oriented knowledge-based economies- a difficult task which in fact includes different elements as: institutional environment for entrepreneurship encouragement, human resources, material and information structure, uniting link in which is the establishment of innovation systems on regional and national levels (Terziev \& Arabska, 2014a).

Examining to what extent state and local strategies in Bulgaria include sustainable development objectives and measures for organic production encouragement and what is their effectiveness some questions are put: Permanently developing legislative base and the whole composition of strategic documents offer the framework but what happens then? Was this framework correctly set? Are the goals and measures implemented in practice or they are just put in order to answer the EU requirements? (Arabska, 2013b). The main strategic documents of the Republic of Bulgaria have been examined in connection to sustainable rural development goals and organic production encouragement and the results are shown as a brief review of priorities and goals put at different levels in the study focused on three main questions: evaluation of the implementation of strategic goals, organic production development in connection to rural development and achievement of sustainability (Arabska, 2013b). The first question assesses the ten most important strategic priorities and goals. The second includes ten factors influencing organic production development in connection to rural development. The third question is about the extent to which organic production could contribute to sustainable development. A qualitative assessment is made rather than a quantitative and a simple method of identification of the most problematic fields which should be paid attention to when formulating strategic priorities and goals is proposed.

Although organic farming is not directly addressed in the general strategic documents, the goals of sustainable development, biodiversity and landscape preservation as the most often stated ones reveal opportunities for organic production development as a way of achieving sustainable growth. In the program of the Bulgarian government 2009-2013 one of the main priorities is development of agriculture as a basis of economic development of the country and particularly increase in the competitiveness of Bulgarian agricultural products in the EU and the whole world, implementation of the main goals of the CAP of the EU through guaranteeing the quality and safety of the production of agricultural raw materials and food, creating conditions for ecological farming protecting environment and biodiversity. One of the actions is increasing the share of organic production and introducing production systems with low inputs and added value outputs.

The stake holders in organic sector - farmers, processors, traders, etc., do not rely on the state financial support. Bulgarian organic production experiences a raise in recent years because of the own initiative of Bulgarian entrepreneurs showing at markets abroad (the main characteristics of Bulgarian organic produce is that it is export oriented as it was mentioned above). The role of the state however was very important in respect to legislative framework and certification which were assured.

The discussed study makes an investigation of the implementation and effectiveness of the strategic documents having relation to organic sector development. As a whole, the experts' assessments show very low and low levels of implementation of strategic goals (Arabska, 2013b). Good and very good results are only given to building quality infrastructure and providing quality education and scientific research activities respectively. The first one is easily explained by the strong governmental policy and support for infrastructure building. The second one relies on the fact that educational and scientific research activities in the country have traditions and success despite the lack of financial resources- they manage to work on many projects and with partners from abroad which still keeps the good level. 
Discussions lead to the conclusion that organic production examined by the three pillars of sustainable development provides: economic sustainability - competitiveness increase, strong market orientation and increase in incomes; social sustainability - bigger responsibility towards consumers' needs, improving quality and safety of food, regional development; ecologic sustainability - a common frame, effective application, control, development of standards of environmental protection, health and welfare (Terziev \& Arabska, 2014b).

Although in progress organic production is not enough for the moment to give the needed rise in rural development. The regions and municipalities' support especially in respect to providing information and motivation is crucial in this process (Terziev \& Arabska, 2015a).

The state should create the favourable environment - permanently updated legislation and policies, information campaigns, opportunities for training, research, technology transfer, good practices exchange, effective control with an accent on risks' evaluation and prevention, etc. (Terziev \& Arabska, 2015b). The encouragement of entrepreneurship in organic farming is closely connected to encouragement measures in processing industry. The development of organic production in the county should be connected to alternative tourism development too providing the great opportunities for this integrated development (Terziev \& Arabska, 2015e). The main problems could be formulated as follows: current strategic documents and key structures in private, state and non-governmental sectors lack coordination. Furthermore they are far away from the problems of organic producers, processors and traders and all this results in all the inadequate measures of support.

\section{ANALYSES OF THE MAIN FACTORS INFLUENCING ORGANIC SECTOR DEVELOPMENT}

Organic sector development is in direct relation with sales but it is influenced by climatic and natural conditions, traditions, motivation, market positions and image, available legislation and its application, organic products marketing, connections and relations between stakeholders in the sector as well as with other sectors and other common factors (investments' opportunities, infrastructure, etc.) (Arabska, 2014b). Investigations of conditions and opportunities for development of organic production and marketing could lead to a summarized analysis of the main factors for organic sector development in a country or a region. The analyses of the main factors in organic sector development in a country or a region could be made in three different aspects (Arabska, 2012) and those are used in the current study for collecting experts' opinion and assessments.

The analyses and the assessments of the main factors in organic production sector development in Bulgaria is made in a few aspects - common development of agricultural sector, factors impeding organic sector development and factors favouring it which are then summarized and on that basis some recommendations are made. The analyses conclude on the main factors' identification and their assessments are made by an expert focus group having additional discussions too.

On agrarian sector development in the country as a whole is influenced by state-of-art of the sector; trends in its development in world scope; application of Common agricultural policy (CAP). For the experts' assessments ten factors are identified as having impacts on agrarian sector. The results show very low levels of administrative and advisory services which is one of the general problems in sector development in the country.

The analyses of the factors impeding organic sector development in the country presents as a main problem the lack of information about quality of products, lack of marketing strategy and advertising and strong competition because of the organic products import (Arabska, 2012). Among the factors favouring sector development in the country the highest significance is put on the legislative base and the sector development potential.

Development of organic production is in direct connection to the sales but it is influenced by the appropriate soil and climatic conditions, traditions, motivation, market positions and producers' image, available legislative base and its application, supply and demand on the market, funding opportunities, organic marketing, relations and interactions between producers, processors, traders, connections to other sector and other common factors (investments, infrastructure, etc.). On the other hand, the consumers' behaviour should be considered too reflecting the factors connected to the safety and quality of products, health concerns and environmental protection: convenience, quality, heath, and ethics. They determine the requirements towards agricultural produce, food and non-food products, marketing, etc.

Concluding on the most general fields in organic sector development, the assessments show the better positions for the legislative base and institutional support. From the analyses regarding organic production 
development in the country examined it could be concluded that there is a very good level of state regulatory mechanisms and access to state and European funding programs, the qualification of staff is not so high and the scientific and research activities and entrepreneurship are assessed on low levels (Arabska, 2012).

Summarizing the analyses the conditions and opportunities for production, processing and trade of organic products in the country, the attention should be on the search of new opportunities for increase in production and motivation, as well as assuring qualified staff in the sector through specialized trainings. Below the conclusions and recommendations about organic sector development are summarized in priority fields of action.

- Financing of activities in agricultural holdings, processing or trade enterprises: It is necessary financial independence to be reached rather than relying on state or EU support. The state should contribute to decrease in administrative burden and creation of favourable business environment. Alternative food networks and community supported agriculture in particular are the alternatives for future development that could provide necessary financial resources for organic production development. Organic production provides many opportunities for applying the concept of community supported agriculture and this is the way of assuring its development in the country. Associations between organic farms (producers) and the society (consumers) in a partnership will provide direct economic and social connections between food production and consumption.

- Market: It is important to stress on the quality of organic products and to make the difference of conventional ones underlining the significance to health and environment and the price of that. However, the price is the main factor in purchase decisions and the great difference and higher prices of organic products would be very difficult to be realized. Special attention should be paid to motivation and support for organic trade in big trade chains, specialized shops, open markets, direct sales, etc., as well as consumption in restaurants. The networking in the sector is an inevitable alternative, especially considering marketing activities, integration to the sector of tourism, etc.

- Motivation: Organizing information campaigns about opportunities and advantages of organic production is absolutely necessary because of the main problem of lack of information and motivation for both consumers and operators.

- Education and training: The need of qualified staff in the examined sector would increase if the trends of sector growth stay the same, especially concerning management, marketing and trade.

- Production and processing: Ways of adding value to organic produce should be sought, particularly in processing. Establishing co-operations, associations, networks- this process should start with provision of information about why and how to do that, presenting good practices, etc.

- Control: The provision of effective control of quality is important to assure consumers trust. A system should be created for administrative and consulting services in this respect for organic producers, processors and traders having an accent on risk assessment and prevention.

Bearing in mind the fact that entrepreneurship is viewed as a basis of sustainable development and knowledge-based economies establishment, for organic sector development the issues connected to entrepreneurship encouragement are discussed with relation to good production practices, management and marketing. Human history evidences show that in entrepreneurship theory and practice there are many tricky questions impeding general conclusions and common recommendations. It is necessary to make analyses in the concrete sector of study or economic activity in order to summarize the necessary characteristics of the entrepreneur, generation of ideas, entrepreneurial strategies, ways of encouragement of entrepreneurial activities, etc. (Arabska, 2014b). In organic sector the bigger part is of innovative and intuitive types of entrepreneurs- full of energy innovators, taking decisions according to the real resources as well as of the analytical types (good organizers, full of ideas, amenable to new information, using integrated approaches). In agricultural sector, and organic farming in particular, the most important decision, is what to produce and in what way. One of the most negative characteristics is the absence of planning in both short and long-term periods. Main mistakes are connected to non-estimated high expenses, lack of managerial and marketing knowledge and skills, lack of integrated knowledge, etc. All above stated as personal qualities, ideas generation, strategies and planning are part of entrepreneurial activities and there should be found ways of improving knowledge, skills and competences in those fields in order to push organic sector development. Starting from the business idea through decision to start organic conversion till extended analyses and planning activities embracing all resources should precede the 'real start' and running. On the other hand, a part of the entrepreneurial potential is the intuitive development of small and medium size business in rural areas based on traditions, culture, experience, etc. Contemporary entrepreneurs should be more wise and 
flexible than ever before, but also honest to customers and socially responsible. Organic production concept and methods fully corresponds to the needs of entrepreneurial, knowledge-based and sustainable behaviour.

The main shortcomings in the establishment and functioning of small and medium-size enterprises in organic sector are determined as follows: big expenses, lack of managerial and marketing competencies, lack of integrated knowledge and approaches, non-compliance to customers' needs and opportunities, unclear vision and goals for future development, etc. All that lead to the following general recommendations for organic sector development through entrepreneurship encouragement: improvement in national legislation (Terziev \& Arabska, 2015c), encouragement measures targeted at small and medium-size enterprises, improvement of advisory services and trainings, information and motivation, etc.

\section{APPROACHES AND INSTRUMENTS FOR ORGANIC MANAGEMENT - A CONCEPT OF IMPROVEMENTS IN THE NATIONAL FRAMEWORK}

Based on the discussions about organic sector development outlining main problems in the country and the need of improvements in the national strategic framework concerning organic production a Concept for implementation of the sustaining role of state and EU funds for the program period 2014-2020 is proposed below.

Bulgaria has favourable opportunities to occupy a merited place in still unfilled market niche of organic products in EU and world. Organic farming is viewed as an alternative for solving the problem of rural depopulation, decrease of employment in agricultural sector and even the problem of unbalanced regional development. While the main problem for agricultural producers in the country are low purchase prices which in most cases hardly cover the cost price of the produce, increasing consumers' demand of organic products creates better opportunities for all the units in the chain of organic production and supply and along with this could give impetus to the local economy and social development in many rural regions in EU countries. Organic sector growth would provide better financial stability of producers, processors, distributors and traders but also would favour directly or not rural communities as a whole. It is advisable an organic farm to combine plant and animal production because that way the most effective use of available resources would be guaranteed, as well as the use of natural cycles in the production. The requirements towards organic produce also impose the conclusion that the whole farm should be organic. This is another implication in the need of cooperation and networking. Measures for improvement of the chains of supply of organic products in the country should be oriented to a strong horizontal and vertical integration among key stakeholders in the sector, for example associations of producers on the country level, on territorial (regional) principle, specialized, etc.

The necessity of the concept is substantiated by the main conclusions about the problems of the development of the sector in the country at the moment which ate interconnected and conditioned are: undeveloped market and infrastructure, low and ineffective use of the money provided by the European funds. Among the reasons of the last ineffectiveness which could be pointed and are common to all the sectors are: complicated application and approval procedures, delays in their implementation, assessments of project proposals and contacting, verification of expenditures and paying back the money, ineffectiveness and insufficiency in the measures of providing information and publicity about application opportunities, as well as the lack of wish of the potential beneficiaries to apply and work on projects. Among the main reasons explaining the lack of interest in the production and consummation of organic products in the country are: low average incomes, low public attention; limited assortment.

Providing favourable climatic, soil and natural conditions, the country has great potentials to develop organic production and the problems are mostly of psychological or economic character. The main problems in increasing the consumptions are the lack of information and the lack of trust in quality, the lack of enough specialized trade objects and their uneven distribution (mostly in big towns), the lack of trademarks and limited assortments.

For producers and processors the main problems are financial and production. Organic production requires significant expenditures on materials, labour force, etc. In primary agricultural production those problems could be more easily solved than in processing industry- hence, the uneven development of both and preponderance of raw materials produced for export.

Development of organic farming would lead to provision of ecological food for the whole society, employment and sustainable incomes for population in rural regions in the following ways: combining traditions and innovation, entering new markets, environmental protection and wise use of resources. Along with the benefits for nature and organisms, the improved landscape in organic areas has a broader social and economic effect. It is an opportunity for making rural regions a more attractive place for living, tourism or recreation. 
As a whole, the necessary prerequisites for achieving sustainable growth through development of organic production regarding legislation, institutions and policies are at a very good level, but there is still a need of changes in positions and actions of local authorities, business and civil society. The change in the value system of operators and consumers is very important but in a direct relation to the standard of living. Although current state of environmental protection in the country and available natural resources is comparatively good and a very important precondition for organic production, it is an object of many impacts and could change very easily and fast in unpredictable scale, even in conditions of very small influences.

The main problems that are mutually connected could be summarized as follows:

- The competition of imported products leads to negative trends and demotivation of producers;

- The activities connected to training, motivation, scientific and research, advisory services, technology and innovation transfer, are not adequate to the processes in economic and public sphere as a whole and regarding priorities set by the government in the sphere of environmental protection.

- The unemployment level is high although the really existing opportunities and resources in agriculture which are not properly used and managed

The ways of overcoming could be:

- Search of the best ways of coordination between the European and national policies and strategies, action plans, etc. consistent with local conditions and peculiarities;

- Giving priority only on economic indicators in conditions in economic crises for stabilization of the national economy is not the right approach, there is a need of integrated approaches.

- Efforts directed to the correct application of law and effective control not only aiming at sanctions but first of all giving recommendations and support for improvements;

- Strategic documents should be permanently revised.

- Entrepreneurship and innovation activity encouragement should be specifically addressed. Training, information and motivation activities should underline the significance of prevention and should not be only focused on the corrective actions.

- The access to training and advisory services in rural regions should be made easier.

Strategies, structures and organizations (in the three sectors- state, business and non-governmental) are not coordinated and are very distant of the problems of organic operators.

The efforts should be focused on the following aspects: creation of better environment for organic sector development and popularization of "ecosystem services”- the real value of preserved nature and effective, long-term and sustainable use of natural resources. There is an urgent need of an action plan for organic production support and encouragement based on the real state-of-art, directed not to financial measure for direct support but to motivation and increase of information, trainings, scientific and research activities, innovation transfer.

Common goal: Creation of favourable business and social environment for development of organic production in the country.

Specific goals: Ease access to information, entrepreneurship encouragement, and innovation activity encouragement.

Scope of the concept: The concept is mostly targeted to activities of information, trainings and publicity of good practices in the field of organic production in the context of sustainable development of rural regions, as well as encouraging scientific and research activity, advisory services and innovation transfer.

Principles: publicity, transparency, comprehensiveness, accountability, control.

The basic model is presented below outlining the need of undertaking activities of information, entrepreneurship encouragement, knowledge and innovation transfer. It stresses on the notion that in the country some concrete structures/bodies should be established on national and local level responsible for advisory services not only in connection to the new program period 2014-2020 but advice of different nature on problems emerging in organic farms and holdings.

Information provision: Because the lack of information is one of the main limiting factors for organic sector development in the country, the organization of informational campaigns both for consumers and operators, 
especially agricultural producers, about the opportunities and advantages of organic production and the processes of conversion.

Prices: Because of the leading role of the prices in purchase decisions and the differences in the prices of conventional and organic products, it is important to underline the quality aspects- importance for health and environment. It is necessary financial independence to be reached by agricultural producers and holdings as a whole, rather than relying on state and European subsidies. The main role of the state should be in decrease of administrative burden and creation of favorable business environment. The policy to be directed towards motivation not on increase of control.

Training: Trainings and motivation should start from kinder gardens and primary schools till university level. It is necessary literature and specialized trainings to be ensured, a good practice are visits to organic farms and taking participation in farm activities by children and young people. For the production, processing and trade in organic there is a need of qualified staff. The training should be oriented towards practice according to the needs of trainees and competence-based. Encouragement of the use of information and communication technology, easier access to innovations, good practices exchange, networking, etc. (Terziev \& Arabska, 2015d). In order to apply into practice the achievements of science, as well as in new products development, it is necessary the active participation of scientific and research organizations in the associations of producers and processors. The connection science-innovation-business should not be of one-direction. Encouragement and provision of knowledge, skills and good practices of cooperation between producers and processors in different forms: marketing, processing and adding value, agro technical facilities and equipment, tourist services, etc.

Distribution: Big trade chains which recently have turned into the main place of purchasing food and nonfood products, dominate over specialized shops, small shops in quarters and markets could expand their assortments to more organic products and attract the attention of customers with advertising campaigns, raising motivation for demand and purchase of organic products. Other opportunities are connected to: restaurants and kitchens offering organic products, targeting also foreign tourists, use of Internet for direct sales, networking for sales and/or processing, integration of organic and tourist activities, etc. The fast development of e-trade should be used in the sector bearing in mind its expansion and opportunities of attracting motivated and solvent customers. Considering negative effects of strongly export orientation of Bulgarian organic production (mostly as raw materials), it is necessary to encourage and support the processing and production of local end-products for local markets.

Control: Ensuring the effective control over production, labelling, distribution and trade for quality assurance and consumers' trust. Creation of a system of services / centers for administrative and advisory services accenting on risk assessments and prevention of negative impacts.

Advisory services: Investigation of consumers' behavior, consultations with organic stakeholders regarding legislative base and support mechanisms, etc. Establishment of specialized mobile consultation centers, training and entrepreneurship encouragement in the sphere of organic production and trade.

Funding opportunities: Vouchers for state and public institutions, employees, etc. Easier access to information about funding opportunities in the new program period. The bodies situated in regional centers would not support enough the sector because they are still "far" of the target groups. The activities should be directed to the active search of contacts in small towns and villages which to be mostly of individual orientation rather than organized information events on some local centers.

Establishment of specialized mobile centres for consultations and entrepreneurship encouragement in the field or organic production is very important. Such kind of an initiative will have success only if stakeholders in the sector unite their efforts and activities - at the moment the established structures lack coordination and are far away from the problems of the operators because they are based in regional centres. The efforts should be in the following aspects: creating favourable administrative and social environment for organic sector development, a common marketing strategy for local markets, popularization of ecosystem servicesthe real price of saved nature and effective, long-term and sustainable use of resources.

\section{CONCLUSION}

Agrarian sector in world scope is standing before a number of challenges connected to globalization processes and competitive environment on international markets grounded by new consumers' demands and behaviour regarding healthy living and added value. Agriculture is a main activity ensuring food and nonfood products characterized by its long historical development marked by inertness and conservatism as a whole, especially in regard to management of agricultural holdings and resources. The negative trends of 
being an unattractive sector lead to rural abandonment and depopulation in last few decades- processes which are characteristic for the examined country far away of its specific history, culture and traditions.

The strategic goals of sustainable economic, social and ecological development interlinked to entrepreneurship encouragement in rural regions in agricultural activities and other connected to them focus on the preservation of components of environment (soil, water, biodiversity, landscape) are targeted to sustainable agriculture and organic farming in particular because it is a realistic way of achieving sustainable development and it has great opportunities to integrate with a number of other economical and noneconomical activities.

Strategic goals of managing demographic problems, rural regions' depopulation, social and economic development of the country could be achieved by smart specialization and transfer of innovations. Agricultural sector and food industry, today more often considered jointly, as well as their integration with tourism, training, etc., have the advantages of both traditions and innovations. The search of sustainable forms of agriculture lead to a strong world growth in organic production (in terms of supply and demand) that at the greatest extent could answer the requirements of protection of environment, human and animal health, as well as provision of food of high quality and safety. Additionally, along with the ecological one, organic production is considered in the entity of economic and social dimensions of sustainable development as a sector having a great potential of rural regions' revival. The problems of financing activities and marketing of produce impose the search of new marketing approaches, mostly in relation to the connection with the consumers at the end of the chain and the finding of an uniting link in the motivation of producers to produce and the consumers to search and purchase organic products.

The main recommendations for encouragement of demand, supply, organic production and trade made in the study and targeted to strategic planning on the national level are focused on raising the level of information and motivation. The notion is that a new policy and strategic documents for organic production development are needed based on the current state of the sector and it should be permanently revised. It should include not only direct financial support measures but mainly measure for motivation and provision of information, trainings, science research activities, transfer of innovations, etc. In this relation the study makes some concrete proposals for new approaches and instruments in terms of a concept for implementation of the sustaining role of state and EU funds for the program period 2014-2020.

\section{REFERENCE LIST}

Arabska, E. (2012). Opportunities for organic food production and marketing in Bulgaria- economic, social and environmental aspects. 50 years FoodRDI International Scientific-Practical Conference „Food, Technologies \& Health" Proceedings Book, 73-83.

Arabska, E. (2013a). Investigation of behaviour, wish and opportunities of operators and consumers for organic production development in Bulgaria, International conference (ICRAE 2013) „Research and education- challenges toward future"; Faculty of Education Sciences, University of Shkodra "Luigj Gurakuqi" in Shkodër; 24-25 May 2013, Albania.

Arabska, E. (2013b). Sustainable rural development through organic production encouragement in state and local strategies in Bulgaria, 4th International Conference of Economic Sciences Quality of Life, Sustainability and Locality; 9-10 May 2013- Kaposvár University- Kaposvár- Hungary, 518-527.

Arabska, E. (2014a). Marketing Strategies in Organic Production in Bulgaria. Discourse Journal of Agriculture and Food Sciences, www.resjournals.org/JAFS, ISSN: 2346-7002 Vol.2 (2):76-84.

Arabska, E. (2014b). Organic production: innovations and sustainability challenges in development framework and management. Lambert academic publishing. ISBN 978-3-659-56379-9.

Goranova, P., Stefanov, S., Tinaneeva, Zh. (2012). Marketing research of the organic products market in Bulgaria. Scientific and applied international conference „Development of agribusiness and rural regions in Bulgaria and EU- perspectives 2020", University of Economics - Varna, 2012.

Kayryakov, N. (2010). Development of organic farming in Bulgaria. Trakia Journal of Sciences, Vol. 8, Suppl. $3,147-152$.

Kuzmanova, Hr. (2012). Competitiveness of Bulgarian agricultural sector in the context of the requirements for sustainable development of rural areas, Scientific and applied international conference 
„Development of agribusiness and rural regions in Bulgaria and EU-perspectives 2020”, University of Economics- Varna, 2012, 242-254.

Nikolova, M. (2012). Organic production in Bulgaria- an innovative solution for creating entrepreneurial initiatives in rural regions, Scientific and applied international conference „Development of agribusiness and rural regions in Bulgaria and EU- perspectives 2020", University of EconomicsVarna, 2012, 231-241.

Production, distribution and consumption of organic products in Bulgaria. A marketing research made by Vitosha Research and published on the web-site of the Ministry of agriculture and food of the Republic of Bulgaria.

Report on the development of organic agriculture in Bulgaria 2014. Ministry of agriculture and food of the Republic of Bulgaria.

Terziev, V., Arabska, E. (2014a). Innovations in organic agriculture for assuring food quality and safety and healthy living environment. Proceeding of International scientific and applied conference Role of economic sciences in society development. UFA, AETERNA 2014, 3-11.

Terziev, V., Arabska, E. (2014b). Organic sector increase and impacts on sustainable development - a myth or a reality? Proceedings of International scientific and applied conference "Contemporary aspects in the globalization of economic processes", 20 December, 2014, UFA-Aeterna, 218-223.

Terziev, V., Arabska, E. (2015a). Challenges to organic production development in the Republic of Bulgaria. 5th International Conference of Economic Sciences, 5th CCEDEP of the ACEU, May 7-8, 2015, Kaposvar, Hungary, 411-423.

Terziev, V., Arabska, E. (2015b). Enhancing competitiveness and sustainability of agri-food sector through market-oriented technology development in Agricultural Knowledge and Innovation System in Bulgaria. III International scientific and technical congress "Agricultural machinery" Varna, 22-25 June 2015, Proceedings Volume 3, 102-105.

Terziev, V., Arabska, E. (2015c). Improvement of national strategic framework in organic production and management in the Republic of Bulgaria. 5th International Conference of Economic Sciences, 5th CCEDEP of the ACEU, May 7-8, 2015, Kaposvar, Hungary, 425-438.

Terziev, V., Arabska, E. (2015d). Opportunities of networking in Bulgarian agri-food sector. Proceedings of 17th International Academic Conference, Vienna, June 21-24, 2015, IISES, 514-526.

Terziev, V., Arabska, E. (2015e). Organic production and management in the Republic of Bulgaria contributing to sustainable development and assurance of safe and healthy living environment. Collective monograph "Socio-economic and law aspects of economy development", UFA-Aeterna, 3-32. 